\title{
On the psychological impact of food colour
}

\author{
Charles Spence
}

\begin{abstract}
Colour is the single most important product-intrinsic sensory cue when it comes to setting people's expectations regarding the likely taste and flavour of food and drink. To date, a large body of laboratory research has demonstrated that changing the hue or intensity/saturation of the colour of food and beverage items can exert a sometimes dramatic impact on the expectations, and hence on the subsequent experiences, of consumers (or participants in the lab). However, should the colour not match the taste, then the result may well be a negatively valenced disconfirmation of expectation. Food colours can have rather different meanings and hence give rise to differing expectations, in different age groups, not to mention in different cultures. Genetic differences, such as in a person's taster status, can also modulate the psychological impact of food colour on flavour perception. By gaining a better understanding of the sensory and hedonic expectations elicited by food colour in different groups of individuals, researchers are coming to understand more about why it is that what we see modulates the multisensory perception of flavour, as well as our appetitive and avoidance-related food behaviours.
\end{abstract}

Keywords: Flavour, Taste, Expectations, Disconfirmed expectations, Sensory, Hedonic, Multisensory

\section{Review}

Under most everyday conditions (excepting perhaps the dine-in-the-dark restaurant; see [1]), consumers have the opportunity to inspect food and drink visually before deciding on whether or not to buy or taste it [2]. Indeed, it has long been recognized that colour constitutes one of the most salient of visual cues concerning the likely sensory properties (for example, taste/flavour) of that which we are about to eat or drink (for example, [3-10]). There is a very long history of colouring being added to food and drink [11-13]. Furthermore, although little studied, those colours that we take to suggest that a food may have gone off can exert a particularly powerful effect on our food avoidance behaviours [14,15]. As such, food colour can be considered as perhaps the single most important product-intrinsic sensory cue governing the sensory and hedonic expectations that the consumer holds concerning the foods and drinks that they search for, purchase, and which they may subsequently consume. ${ }^{a}$

At the outset, though, it is important to distinguish clearly between taste and flavour, two terms that are used more or less interchangeably in everyday language $[16,17]$. The reason being that colour cues appear to

Correspondence: charles.spence@psy.ox.ac.uk

Crossmodal Research Laboratory, Department of Experimental Psychology, University of Oxford, 9 South Parks Road, Oxford OX1 3UD, UK have a somewhat different effect on taste versus flavour perception (see [18], for a review). Strictly speaking, 'taste' refers to the perception of sweet, sour, bitter, salty, and the other basic tastes, which are detected by the gustatory receptors found primarily in the oral cavity. By contrast, 'flavour' refers to those experiences that also involve a retronasal olfactory component, such as meaty, burnt, floral, fruity, citrusy, and so on (see [17]). However, confusing matters somewhat, in everyday language, people typically use the term taste to describe their overall experience of food and drink. Here, the terms are used with their more precise scientific meaning.

A growing body of scientific research now suggests that our experience of taste and flavour is determined to a large degree by the expectations that we generate (often automatically) prior to tasting [19-21]. Such expectations can result from branding, labelling, packaging, and other contextual effects (that is, from a host of product-extrinsic cues) but also from a variety of product-intrinsic cues as well. The smell and aroma of food and drink are clearly important here, as are, on occasion, the sounds of food preparation (see [22], for a review). That said, olfactory cues can often be obscured by product packaging, and the products on the supermarket shelf rarely make any sound when inspected visually. Hence, it is vision, and most often colour, that is the cue 
used by the brain in order to help identify sources of food and make predictions about their likely taste and flavour $[20,23]$. Or, as the spokesperson for the Institute of Food Technologists put it a few years ago: 'Color creates a psychological expectation for a certain flavor that is often impossible to dislodge.' [24].

The focus in this article is on the psychological effect, or better said, effects, that food colour exerts over the mind and behaviour of the consumer. The review starts by looking at the effect of food colouring on sensory expectations and hence on people's judgments of taste/flavour intensity and flavour identity (see [18], for a review). The literature on off-colours in foods and drinks is reviewed briefly, and popular concerns regarding artificial food colouring highlighted. Attention will be drawn to research showing the important individual differences in terms of the meaning, and hence psychological influence, of colour in food. Along the way, some of the problems associated with the interpretation of much of the laboratory research that has been conducted to date will be highlighted.

Although falling beyond the scope of the present review, it is worth noting that colour is but one aspect of vision's influence over taste and flavour perception. Researchers have, for instance, reported that people tend to judge the freshness of fish, in part, based on the luminance distribution (that is, the glossiness) of fish eyes [25]. The luminance distribution also appears to be an important cue for judging the freshness of certain fruit and vegetables as well [26]. The influence of visual food texture on people's sensory perception and consumption behaviour has also been studied by researchers [27-29]. However, given space constraints, the focus here will be squarely on colour and its psychological impact on the perception/behaviour of the consumer.

\section{Psychological effects of food colour: setting sensory expectations Taste/flavour intensity}

It would seem reasonable to assume that wherever in the world one finds oneself, more intensely coloured foods are likely to be more intensely flavoured. What also seems likely is that consumers will have picked up on this statistical regularity in the environment and hence will tend to expect that more intensely coloured foods and beverages (not to mention the packaging in which such products come) will have a more intense taste/flavour. Should those expectations not be met, then a negatively valenced disconfirmation of expectation response may well ensue (for example, [30-32]). ${ }^{\mathrm{b}}$ Over the last 50 years or so, a large body of laboratory research has demonstrated that adding more colouring to a food, or more often, to a beverage (see [33], for a review), can lead the participants in laboratory research to rate the taste and/or flavour as more intense (for example, [18,34-38]).
The addition of food colouring influences sensory thresholds for certain of the basic tastes. In one classic study, Maga [39] demonstrated that adding food colouring (red, green, or yellow) to an otherwise clear solution exerted a significant effect on thresholds for the detection of certain of the basic tastes when presented in solution. Adding green food colouring decreased people's detection threshold for sourness, while at the same time increasing the threshold for the detection of sweetness. The addition of yellow colouring reduced the detection threshold for both sourness and sweetness, while the addition of red colouring reduced the threshold for the detection of bitterness. ${ }^{\mathrm{c}}$ Intriguingly, the threshold for the detection of salt was unaffected by the addition of food colouring. Maga's [39] suggestion at the time was that this null effect resulted from the fact that salty foods are associated with foods of many different colours and hence that salt is not associated with a particular colour. As Maga himself put it: 'numerous foods of varying color can be characterized as tasting salty, examples would be pretzels (brown), potato chips (yellow), popcorn (white), olives (green, black), and pickles (green).' ([39], p. 118). That said, more recent research has clearly demonstrated that most people do tend to associate salt with the colour white (see [40]). Perhaps, then, had Maga tested a different range of colours, he might have come to a somewhat different conclusion.

Perhaps the most convincing evidence published to date concerning the influence of food colouring on ratings of taste intensity comes from research published by Clydesdale et al. [41]. These researchers conducted a number of psychophysical studies showing that the addition of food colouring can deliver as much as $10 \%$ perceived sweetness. Indeed, such results have led some to wonder whether food colouring could be used as an effective means of reducing the sugar content of foods. While this is certainly a theoretical possibility, it is worth bearing in mind that the majority of the studies that have been published to date have involved fairly short-term exposure to particular combinations of colour-taste/flavour. While demonstrating that food colouring has an impact on sweetness perception in the short term is one thing, it is quite another to convincingly demonstrate that it will necessarily have psychological effects that last over the long term (cf. [42]). Hence, longer-term follow-ups are most definitely in order. What is more, as the studies discussed below make only too clear, psychological effects of food colouring on the perception of taste and flavour intensity have not always been demonstrated.

One null result in this area was reported by Norton and Johnson [38]. These researchers manipulated the intensity of four typical drink colours. They were unable to find any meaningful relationship between the intensity of the colour and flavour ratings on either a sweet-sour scale or on a distinct-indistinct flavour scale in the 18 participants whom 
they tested. Meanwhile, Lavin and Lawless [43] investigated the influence of varying the intensity of food colouring on ratings of sweetness intensity. The participants were given two pairs of strawberry-flavoured drinks to compare and to rate in terms of their sweetness, using nine-point scales. One pair of drinks was light and dark red, whereas the other pair was light and dark green. The drinks were equally physically sweet, varying only in terms of their appearance properties (that is, colour). Those adults who took part in this study rated the dark-red and light-green drinks as tasting sweeter than the light-red and dark-green samples, respectively. By contrast, colour intensity had no effect on the responses of 5- and 14-year-old children. Elsewhere, Alley and Alley [44] similarly failed to demonstrate any effect of the addition of colour (red, blue, yellow, or green) to an otherwise colourless base (either liquid or solid) on the perceived sweetness of sugar solutions in a group of 11 to 13 year olds.

In a study by Philipsen et al. [45], a group of young adults (aged 18 to 22 years) and a group of older participants (aged 60 to 75 years) rated a number of attributes (for example, sweetness, flavour intensity, flavour quality, flavour identification, and so on) of 15 samples of an artificially flavoured cherry drink that varied in terms of its sucrose content, flavour, and colour. Interestingly, variations in colour intensity had no effect on sweetness ratings in either age group but did impact on flavour intensity ratings in the older participants.

In another study, Chan and Kane-Martinelli [46] examined the effect of food colouring on perceived flavour intensity and acceptability ratings in samples of chicken bouillon and chocolate pudding. These foods were presented with no colour added, with the normal (that is, commercial) level of food colouring, or with twice the normal level of colour added. The participants tasted and evaluated the three samples of either food, using visual analogue scales. Younger adults (20 to 35 years of age) were found to be more affected by the presence of food colouring than were the older adults (60 to 90 years of age). Interestingly, the younger group's judgment of the overall flavour intensity of the chicken bouillon was influenced by the amount of colouring that had been added to the sample.

Zampini et al. [47] conducted a study in which a group of adults had to try and identify the flavour of a variety of drinks and rate perceived flavour intensity using a labelled magnitude scale. The drinks were flavourless, or else had an orange, lime, or strawberry flavour, and could be presented as colourless solutions, or else artificially coloured red, green, or orange. The food colouring was added at either a standard or double concentration. However, variations in the intensity of the food colouring (no matter whether that colour was appropriate or inappropriate to the flavour of the drink) had no effect on the perceived flavour intensity. That said, the addition of inappropriate food colouring significantly impaired the accuracy of participants' flavour identification responses (see Figure 1), thus suggesting that the participants were unable to ignore the colour of the drinks completely, as they had been encouraged to do by the experimenter.

To date, the majority of the research on the psychological influence of colour on judgments of taste/flavour intensity (not to mention flavour identity, see below) has been conducted with beverages. This is presumably because it is easier to manipulate the level of colour in solutions [33]. That said, intriguing research by Shermer and Levitan [48] has recently demonstrated that people also expect more intensely red-coloured salsas to be spicier (that is, more piquant). In fact, over the last 80 years or so, researchers have looked at the psychological impact of food colour on everything from noodles [49] through vegetables [50] and from cheese [51] through to yoghurt [34,52], not to mention cake [53], jams, jellies, chocolates, and sherbets $[7,54,55]$.

One final point to note here is that it may be important to pay careful attention to the methodological details from the various studies of the psychological effect of colour on flavour intensity. The reason being that one study has obtained differing effects of food colour on orthonasal and retronasal judgments of a commercial fruit-flavoured water drink [56]. In particular, colouring a tangerine-pineapple-guava-flavoured solution red led to odour enhancement in those participants who sniffed the odour orthonasally, while giving rise to a reduction in perceived odour intensity when the same olfactory stimulus was presented retronasally instead.

Koza et al. [56] attempted to account for this surprising pattern of results by suggesting that it may be more important for us to correctly evaluate foods once they have entered our mouths, since that is when they pose a greater risk of poisoning us. By contrast, the threat of poisoning from foodstuffs located outside the mouth is obviously going to be less severe. Whatever the explanation for Koza et al.'s results turns out to be, the main point that these results highlight is that one cannot simply assume that colour's effect on orthonasal olfactory judgments of a food or drink's flavour will necessarily be the same when people come to actually taste it.

\section{Interim summary}

As the results reviewed in this section have made only too clear, the psychological effects of either adding or changing the intensity of food colouring on the intensity of taste/flavour perception are not altogether clear. Null results have been obtained by some researchers (for example, $[44,57])$. And even those who have obtained significant effects of colour on taste/flavour intensity ratings/perception have tended to do so only under a subset of experimental 


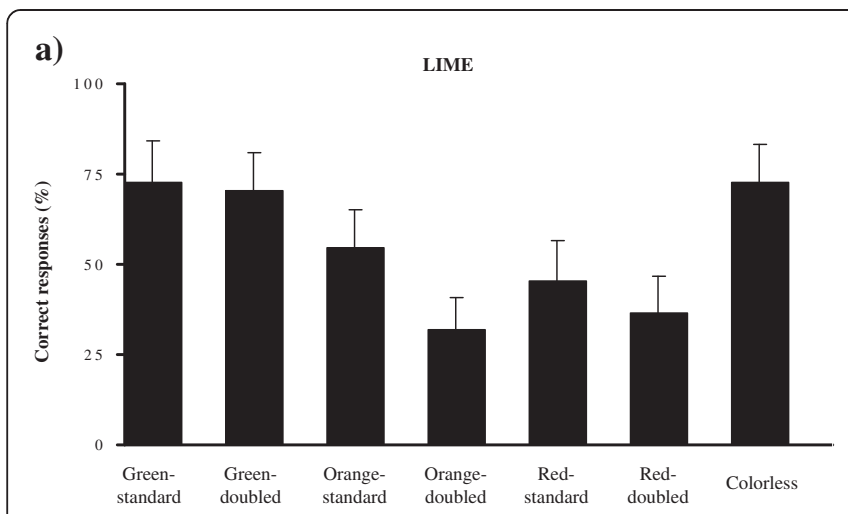

Color of the solutions

b)

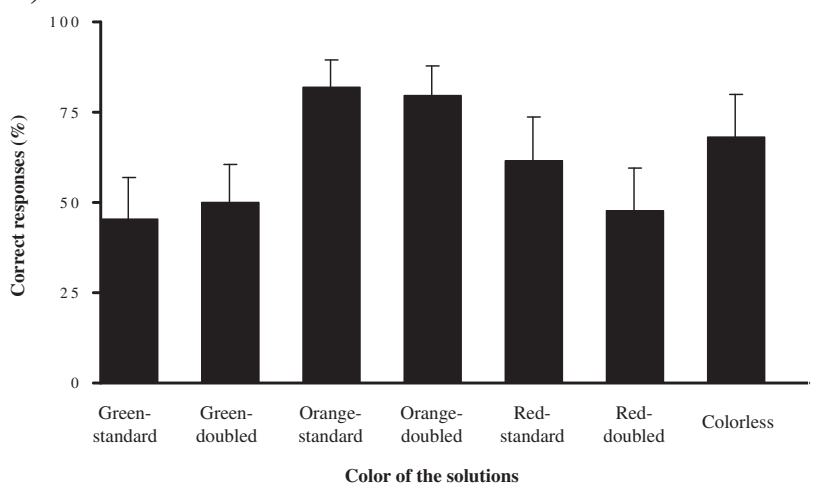

c)

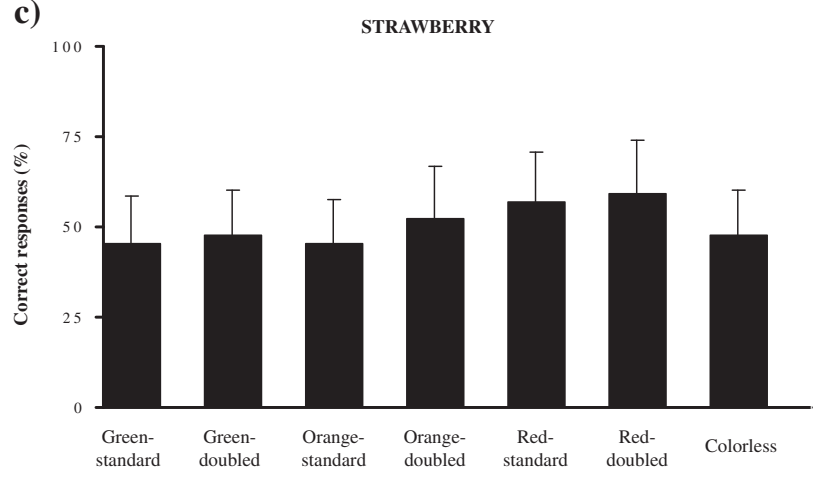

Color of the solutions

d)



Figure 1 Mean percentage of correct flavour discrimination responses for the lime (a), orange (b), strawberry (c), and flavourless (d) solutions presented in Zampini et al. ([47]; experiment 2). The error bars represent the between-participants standard errors of the means. These results clearly show the deleterious effect of adding the inappropriate food colour on participants' flavour identification responses, at least for the lime- and orange-flavoured drinks. (Somewhat surprisingly, the addition of food colouring had little effect on the accuracy of participants' flavour discrimination responses for the strawberry flavoured solution). Critical to the present discussion, increasing the intensity of food colouring had no effect on flavour identification, nor on judgments of flavour intensity. (Figure reprinted with permission from [47]).

conditions or else in a subset of those individuals whom they have tested (for example, see [39,43,45-47,53,58-66]). As such, it is difficult to draw any overarching conclusions from the range of results that have been published to date as to when exactly the addition of food colouring will influence ratings of taste/flavour intensity. Clearly, the addition of food colouring can influence thresholds and ratings of stimulus intensity. However, when exactly such crossmodal effects will be observed is harder to predict with any confidence. ${ }^{\mathrm{d}}$ Indeed, one question left unresolved by much of the research that has been published to date in this area concerns why it is that these seemingly inconsistent results might have been obtained in the first place. According to Koza et al.'s [56] findings, part of the answer might relate to methodological details concerning whether olfactory stimuli are presented orthonasally or retronasally.

However, perhaps, one also needs to take a step back and consider what happens if the sensory expectations set by the intensity of food colouring fail to match up with the experience when a food or beverage item is actually tasted by the participant or consumer. In the real world, this might be expected to give rise to a negatively valenced disconfirmation of expectation response [21,31,32]. However, in much of the laboratory research published to date, there is a question as to whether the participants actually believed that the colours of the foods or drinks that they were tasting had any meaning - that is, to what extent did they really believe that the food colouring they saw was linked to the actual taste/flavour of the drinks that they were tasting? (One might also be tempted to wonder whether or not participants noticed any discrepancy between what they saw and what they tasted [67]). While such an assumption is presumably likely out there in the real world, it is not so clearly the case for those participants taking part in laboratory research where they may have been exposed to a whole series of inappropriately coloured samples to taste and evaluate over the course of their experimental session. What is more, the research varies between those studies in which the researchers have been very explicit about the fact that the colour cues were designed to be misleading $[47,68]$, through to those who have done their utmost to 
hide the purpose of their study (and the potentially misleading nature of the colours) from their participants [69].

\section{Flavour identity}

Perhaps the most robustly demonstrated effect of adding (or changing) food colouring has been on people's identification of the flavour of food or, more commonly, drink (see [33], for a review). Classic research by DuBose and his colleagues [53] demonstrated that the addition of food colouring (green, red, or orange) biased participants' judgments concerning the identity of the flavour of a cherry-flavoured solution. So, for instance, nearly $20 \%$ of the participants in this study reported that the drink tasted of orange when the cherry-flavoured solution was coloured orange as compared to no such responses when the same drink was coloured red, green, or remained colourless. Meanwhile, colouring the same drink green led to $26 \%$ lime-flavoured responses as compared to no such responses when the drink was coloured red or orange (see also $[10,70,71]$, for similar results).

Oram et al. [67] gave over 300 people (of various ages) four drinks to taste. Four possible drink flavours (chocolate, orange, pineapple, and strawberry) were presented in four different colours (brown, orange, yellow, and red), thus giving rise to a total of 16 possible drinks. The participants had to try and discriminate the flavour of the drinks. The results highlighted a clear developmental trend toward an increased ability to correctly report the flavour of the drinks, regardless of the colour in which the drink was presented (see Figure 2). That is, the crossmodal modulation of flavour perception by vision apparently decreased with age (from 2 years of age up).
Importantly, in this and the majority of the other studies that have been reported so far, the participants were given no information about the possibility that the colour of the solutions might have been misleading (a point to which we will return later). Research by Zampini et al. $[47,68]$ has shown that adults can easily be confused by the addition of inappropriate colour to a range of fruit-flavoured soft drinks (see Figure 3). Importantly, the crossmodal effects of beverage colour on flavour identification demonstrated by Zampini et al. were obtained under those conditions where the participants had been told to ignore the potentially misleading colouring of the beverages that they had been presented with. Such results therefore hint at the automaticity of such crossmodal effects.

\section{Interim summary}

The majority of the research that has been published to date has convincingly demonstrated that food colour affects the ability of people to correctly identify the flavour of food and drink (see Spence et al. [18], for a comprehensive review of the literature on this question). Although beyond the scope of this review, it is perhaps also worth noting that food colouring can influence the perceived thirst-quenching (or refreshing) properties of drinks as well $[41,72-74]$. That said, I would argue that there is a danger that one can get a biased impression of just how important colour is to the consumer's perception of, and response to, food and drink. This is because in the majority of laboratory studies, the colour of the foodstuff was pretty much the only cue, sensory or otherwise, that the participants had to go on when making their decisions as to the taste/flavour of that which

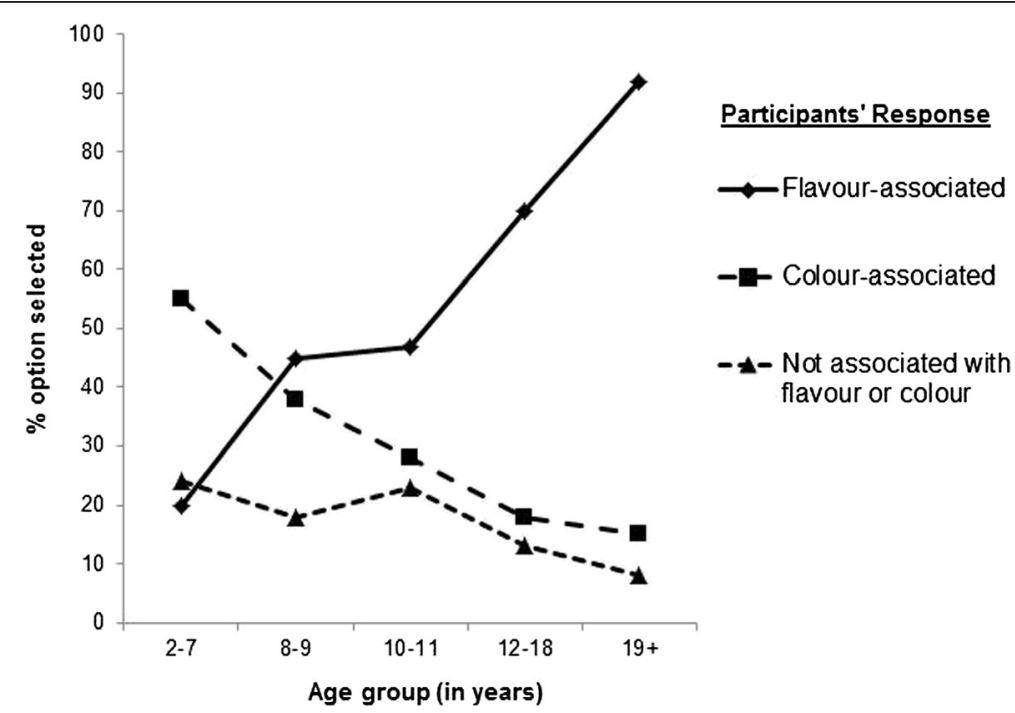

Figure 2 Graph highlighting the percentage of trials in which the participants' flavour discrimination response matched the colour of the drink, the actual flavour of the drink, or matched neither the colour or flavour of the drink as a function of the age of the participants in a developmental study of the psychological impact of colour on people's flavour discrimination responses reported by Oram et al. [67]. [Reprinted from [67], with permission]. 


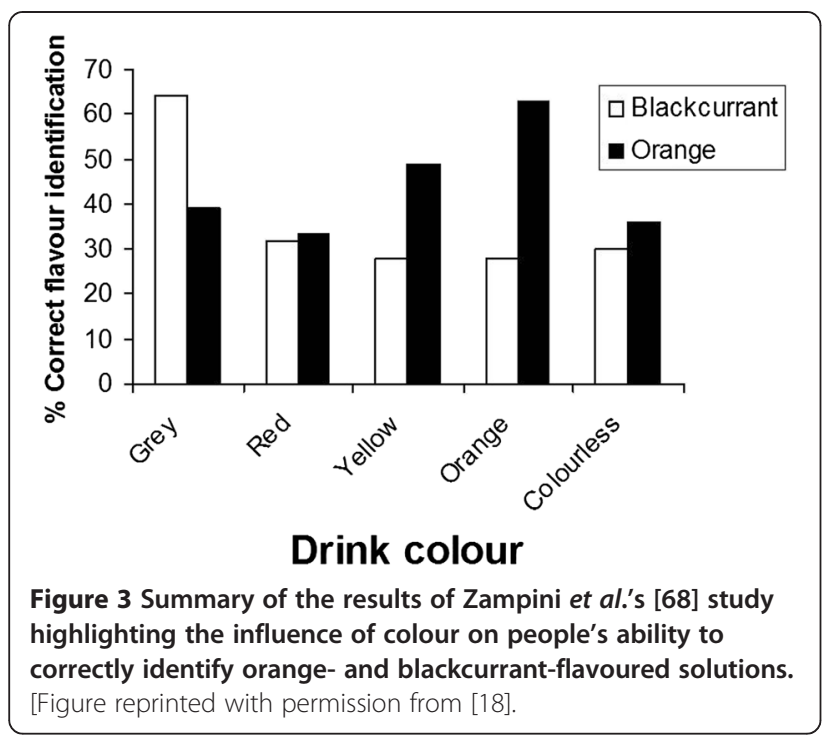

they were tasting. In the real world (see below), the consumer normally has a number of other cues to utilize when trying to judge the likely sensory and hedonic qualities of food and drink. What is more, there is always a danger that being confronted with a whole range of drinks, say, similar in flavour and differing most noticeably in terms of their colouring may have drawn, or focused, the participants' attention on colour as the most salient dimension (that is, in a way that may not be representative of everyday life).

One other thing to note here is that food colours are not necessarily associated with just one taste/flavour. As shown by Zampini et al. [47], for example, a red-coloured drink may be most strongly associated with the flavour of strawberry, but also, to a lesser degree with the flavour of raspberry and cherry. Hence, if one really wants to understand/ predict its effect on multisensory flavour perception, it is important to bear in mind that a given beverage colour may actually prime a number of different possible flavours [75-78]. What is more, similar food colours may give rise to qualitatively different flavour expectations depending on the category of product under consideration (for example, soft drinks, cake, noodles, curry, and so on) and possibly also the brand (cf. [79]). As such, there is clearly a need for more research addressing the influence of food colour across different kinds of food product (and as a function of branding) in order to get a more complete, not to mention market-relevant, understanding of the psychological effect of food colour.

\section{Names, brands, and colours}

Given the ambiguity in the meaning of colour in foods and beverages, it can sometimes be important that the name and description of a food or beverage set the right sensory or hedonic expectations or else help to disambiguate between the different possible meanings that may be associated with a given colour. The classic example here comes from the work of Yeomans and colleagues [80]. These researchers demonstrated that when the meaning of food colouring is misinterpreted (that is, when it sets the wrong sensory expectations), then this can have an adverse effect on people's subsequent taste ratings. The participants in this study were given a bright pink ice cream to taste. One group of participants was given no information about the dish, another group was informed that the food was called 'Food 386', and a third group was told that what they were about to eat was a frozen savoury mousse. Those participants who had not been given any information about the dish and hence who were led by their eyes into expecting that they would taste a strawberry-flavoured ice cream (which has the same pinkish-red colour) did not like the dish when they tried it. Specifically, they rated the frozen savoury smoked salmon ice cream as tasting too salty. By contrast, those participants in the other two groups rated the seasoning of the dish as being just right, and, what is more, liked the savoury ice far more as well (see [81-83], for related research). These results therefore demonstrate that the meaning of colour in food and drink can be altered simply by the description that is given to a product or dish [1]. Generally speaking (that is, in all environments excepting perhaps the modernist restaurant), it is important to avoid disconfirmed expectation [1,84].

Indeed, the typical laboratory situation can be contrasted that with that of everyday consumption episodes where a food or drink will most likely be encountered in the context of branding/packaging information, or may well have been described by whoever has prepared, or is serving the food or drink. In other words, it can be argued that the situation that is typically studied in the laboratory setting is quite unlike that of everyday life (see also [85-87]). Hence, one concern here is that the results of much of the research that has been conducted in the laboratory may actually end up giving a biased view of the importance of colour in multisensory flavour perception. Note that in the laboratory situation, colour is often the only cue that participants have to go on when making their judgments of expected flavour. By contrast, in the majority of real-world consumption situations, colour is but one of many cues (including branding, pricing, labelling, and so on) that the consumer can use.

One other product-extrinsic cue that can modulate the meaning of colour in beverages is the nature of the glass or receptacle in which that drink happens to be presented $[88,89]$. The same colour drink may have a very different meaning if shown in a plastic bathroom cup than in a cocktail glass, say. In the former case, a blue-coloured drink is likely to be interpreted as connoting mouthwash and hence associated with a mint flavour, whereas when exactly the same colour is seen in a cocktail glass, it may 
be interpreted as signifying the orange flavour of blue curaçao instead [90].

\section{Psychological effects of food colour on behaviour}

It is important to realize that the psychological effects of food colouring are not restricted to the sensorydiscriminative domain. It has often been suggested that food colouring can modulate certain of our food-related behaviours as well [91,92]. Certainly, getting the colour right can play an important role in food acceptance, liking, and hence, ultimately, food intake [24,93-97]. Though, as pointed out by Garber et al. [85], while it is often claimed that colour influences food preferences, good, marketingrelevant insights tend to be a little harder to come by in this area.

Colour can play an important role in modulating a consumer's affective expectations [32,98]. And just as there can be a sensory disconfirmation of expectation (as outlined above), there can also be a hedonic disconfirmation of expectation - that is, when a consumer realizes that they do not like a food or beverage as much as they were expecting that they would.

In other research, it has been shown that people will consume more candy if it comes in a variety of colours than if presented in just a single colour [99], even if that colour happens to be the consumer's favourite one. Whether sensory-specific satiety or boredom is the most appropriate explanation for such results is still being deliberated by researchers (see [92], for a review). Interestingly, while the use of colour (specifically increasing colour variety) is usually portrayed as a means by which the big food companies can get their consumers to consume more (think only of the multicoloured packs of Smarties, M\&Ms, or Jelly Beans), there is some evidence to suggest that colour cues can also be used to modulate intake downward, by providing an effective cue to portion control ([100] see also [101,102]). So, for example, Geier et al. [100] reported that people ended up eating fewer potato chips if every seventh chip in a tube happened to be coloured red.

\section{Off-colouring in food}

Researchers have been interested in the response of consumers to food colouring that they associate with products that have been in some way spoiled. That such off-colours can have a profound effect on people's food behaviours was suggested by the response of consumers to a batch of Tropicana grapefruit juice that was donated to a food bank some decades ago. According to Crumpacker ([14], p. 6), nobody wanted to drink the juice because of its abnormal brown colour. This despite the fact that those who tried it reported it to taste perfectly acceptable; see also $[59,81,103]$, on the preferred colour of this staple of the breakfast table.
Meanwhile, the dinner party guests in Wheatley's [15] classic study were invited to dine on a meal of steak, chips, and peas. The only thing that may have struck any of the diners as odd was how dim the lighting was. However, this aspect of the atmosphere was actually designed to help hide the food's true colour. Part-way through the meal, the lighting was returned to normal, revealing that the steak had been artificially coloured blue, the chips looked green, and the peas had been coloured red. A number of Wheatley's guests suddenly felt ill when the lighting was turned to normal levels, with several of them apparently heading straight for the bathroom (cf. [54]). ${ }^{\mathrm{e}}$

It is noticeable how the majority of the research on the psychological impact of off-colour in food is rather anecdotal in nature (presumably because it can be difficult to get ethical approval to present food to participants and have them believe that the colour indicates that it has gone off). Nevertheless, the evidence that has been published to date does seem to highlight the strong avoidance responses that such food colouring can induce, especially in the case of meats and fish that look off. ${ }^{\mathrm{f}}$

\section{Artificial/natural}

Over the years, there has been ongoing concerns expressed about the negative health and well-being consequences that are apparently associated with the consumption of certain artificial food colourings, this despite their being rated as being safe and tasteless [24,104-116]. This had led some consumers to search out those foods that are free from all colouring. However, such products generally do not taste that good. As Harris pointed out in an article that appeared in The New York Times [24], many commercial foods are disappointingly lacking in taste/flavour if served in a colourless (that is, clear or white) format.

A less extreme reaction to concerns over artificial food colourings has been to search out natural colourings that better match the sensory properties desired by the food producers: This includes everything from trying to deliver a wide enough range of natural colours [117], through to improving the stability of natural colourings, at least for those products that are likely to have a long shelf life [118-120]. Of course, that food colouring is natural does not in-and-of-itself necessarily make it appealing to the consumer. Here, one only needs to think of the red colouring of, for example, Smarties (the candycovered chocolate; http://www.nestle.co.uk/brands/chocolate_and_confectionery/chocolate/smarties) that used to be made from carminic acid extracted from scaly insects. Unappealing to most consumers, one imagines. Nowadays, though, the red colouring comes from red cabbage instead [116]. 
And what, exactly, constitutes natural is not obvious. The vibrant orange-coloured carrots that we are all familiar with nowadays, for example, are actually the result of extensive breeding. Once upon a time, the majority of carrots were naturally purple. According to some, the selective breeding was designed to deliver the orange colour of the Dutch royal family in the seventeenth century [121-123]. Although another, perhaps more plausible, explanation for why the orange variety may have been preferred over the original purple variety was because the latter would colour the soups, stews, and so on into which they were placed.

A number of the modernist chefs we have been fortunate enough to work with here at the Crossmodal Research Laboratory at Oxford University over the years have been particularly interested in surprising their diners by presenting foods that have one colour (and hence set a particular taste/flavour expectation) while actually delivering another unexpected flavour instead. ${ }^{\mathrm{g}}$ However, the chefs typically do not want to achieve such results by means of artificial food colourings for fear of their diners' reaction.

One elegant example of the use of natural colouring to create surprise and delight in the mind of the diner comes from the beetroot and orange jelly dish that used to be served as one of the opening courses on the menu at The Fat Duck restaurant in Bray (http://www.thefatduck.co.uk/). This dish would be presented as two blocks of jelly, one bright orange, the other a dark purple, placed side-by-side on the plate. And where the modernist chefs lead, the market sometimes follows. Pine berries, for example, which look for all-the-world like white strawberries provide an intriguing example of an otherworldly, at least to Western eyes, but entirely naturally coloured food. ${ }^{\text {h }}$ Such unusually coloured food products have apparently been selling well in the supermarkets in recent years (see also [123]). More generally, there would appear to be renewed interest in surprisingly coloured foods in the mass market as well. For example, a few years ago, one well-known burger chain launched a pitch black bamboo and squid ink burger in Japan, that was seasoned with black squid ink ketchup, and served in a black bun [124]. As a group, children seem to be particularly fond of such miscoloured foods (think confused Skittles; http://www.wrigley.com/ uk/brands/skittles.aspx) and beverages [125-128].

\section{Marketing colour}

Adding colour to food or else changing the colour of a food or beverage (or its packaging) has long been used as a marketing tool (for example, [129-133]; see also http:// www.ddwcolor.com/hue/why-color/). In fact, according to an informal store audit reported by Garber et al. [85], 97\% of all food brands displayed (in all categories) used food colour to indicate flavour. Food colour is used in marketing for a number of reasons: Everything from increasing shelf stand-out through to blurring the distinction between different products. Indeed, going back three quarters of a century now, there was quite a fight by the butter lobby in order to try and prevent the makers of margarine from adding a golden yellow hue to their product in order to give it the appearance of its better established rival (for example, see [134]).

More recently, the potential role of adding food colouring in marketing was amply demonstrated by the dramatic rise in sales of tomato ketchup when Heinz decided to add a tiny amount of food colouring and turn this staple of the dining table green [135]. Other large drink brands that have, in recent years, launched drinks in unusual colours include an amber-coloured cola, called Pepsi Gold, in India [133]. However, not every attempt by marketers to use colour to boost sales has been successful. Clear cola drinks, for example, have generally failed in the marketplace [136]. And while there are a number of theories out there in the marketing literature about what went wrong in such cases, one suggestion is that when such drinks were tasted away from their packaging then the likely disconfirmation of expectation that results from experiencing a cola flavour when the sight of the drink led the consumer to expect lemonade or soda water may have been especially problematic. ${ }^{i}$

\section{Individual differences in the psychological effects of colour}

One thing that is noticeable about much of the early research on the psychological effects of food colouring is how little attention was paid by researchers to the profiles of the participants themselves. This turns out to be an important caveat since the latest research now shows that exactly the same food colour can elicit qualitatively different expectations concerning the likely taste/flavour of food and drink in different groups of consumers.

\section{Cross-cultural differences}

Exactly the same colour (for example, in a beverage) has been shown to set up qualitatively different expectations in the minds of different (groups of) consumers. Just take the two drinks shown in Figure 4: When they were shown to young adults in Taiwan and the UK, the former expected them to taste of cranberry and mint (mouthwash?), respectively, whereas the latter expected cherry/strawberry and raspberry, instead [75]. Wan et al. [88,89] have recently been conducting a number of internet-based studies designed to assess which food colours have a similar meaning in terms of expected flavour across culture and which differ markedly in terms of the expectations that they set. Food marketers working in the global marketplace obviously need to be aware of any cultural differences in the meaning of food colour [133]. Here, though, one potential 


\section{Cross-cultural colour-flavour associations}
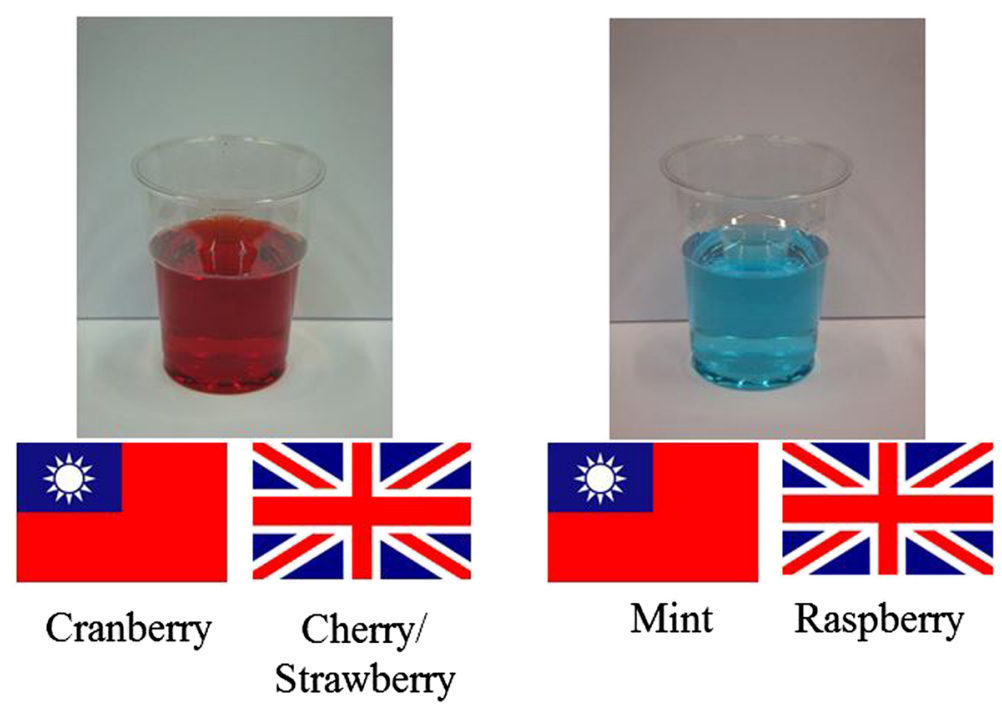

Figure 4 Two of the six coloured drinks shown to the participants from the UK and Taiwan in a study by Shankar et al. [75]. The results of this cross-cultural study demonstrated that exactly the physically same food colour can elicit qualitatively sensory different expectations as far as the likely flavour of a drink might be in consumers from different countries. The most frequently expected flavours for drinks of these colours are shown at the bottom.

limitation with the internet-based testing of consumers' colour expectations ought to be noted: Namely, it is difficult to precisely control the appearance properties of the visual stimuli on an individual participant's monitor. By contrast, in Shankar et al.'s [75] study, the participants actually viewed the drinks.

\section{Developmental differences}

Developmental differences in the meaning, and influence, of food colour have been reported by researchers. As noted earlier, young children seem to be more drawn to brightly (some would say artificially) coloured foods than are adults (though see [90]). In terms of changes in the psychological influence of food colouring across the lifespan, on the basis of the evidence that has been published to date $[45,67,137]$, it would appear that, if anything, visual cues exert a somewhat greater influence on flavour identification early in development (see Figure 2), and in old age, than in adulthood (see [138], for a review). One reason as to why children might show more visual dominance (that is, simply relying on what they see) is because they have not yet learned to integrate their senses in an adult-like manner (cf. [139]). Thus far, published studies have assessed the responses of children from 2 years of age upward.

At the other end of the spectrum, the well-documented decline of taste and smell sensitivity in old age may mean that the residual senses (especially those where prostheses, such as glasses or hearing aids, are available) take on a more important role in terms of determining the final taste/flavour experience $[3,137]$. However, it has to be said that the evidence that has been published on this topic to date is rather mixed (see [138], for a review). While some researchers have been able to demonstrate more pronounced psychological effects of food colouring in, say, older adults $[45,103]$, such differences have certainly not always been found.

Here, it is perhaps also worth bearing in mind that there may be changes in the meaning and acceptability of colour over time. One only needs to remember, for example, that blue foods were traditionally considered unacceptable to a majority of consumers [140,141]. Nowadays, many foods are blue [133], although in this case, note that they are primarily marketed at the younger consumer [85]. Over a much longer timescale, one could even think of how the flavour of carrots may have switched its colour association from purple to orange (see above).

\section{Expertise and the psychological effects of food colouring}

Expertise has been shown to modulate the psychological impact of food colouring on flavour perception. Some of the most impressive studies have come from the world of wine (see [142], for early research; and [143], for a review). In one oft-cited experiment, Morrot and his colleagues [144] reported that a group of students on a university wine course in Bordeaux, France, had been fooled into choosing red wine aroma descriptors when given a white wine to evaluate that had been artificially 
coloured red with odourless food dye. Meanwhile, Parr et al. [145] conducted a follow-up in New Zealand in which they tested both experts (including professional wine taster and wine makers) and 'social' drinkers. The descriptions of the aroma of a Chardonnay wine given by the experts when it had been artificially coloured red were more accurate when the wine was served in an opaque glass than when served in a clear glass. Interestingly, this colour-induced biasing of flavour judgments occurred despite the fact that the experts had been explicitly instructed to rate each of the wines that they had been given to taste while ignoring any colour cues. Such results therefore suggest that the crossmodal effect of vision is not under cognitive control. Ironically, the social drinkers in Parr et al.'s study turned out to be so bad at reliably identifying the aromas present in the wine that it was difficult to discern any pattern in the data when an inappropriate wine colour was added.

Taken together, therefore, the evidence that has been published to date is consistent with the view that expert wine tasters differ from social drinkers (that is, nonexperts) in the degree to which visual (colour) cues influence their orthonasal perception of flavour [145] and their perception of the taste of sweetness ([142]; see also [84]). That said, it is worth noting that not all food/flavour experts necessarily exhibit the same increased responsiveness to colour cues when evaluating the taste and flavour of food and drink. Shankar et al. [78], for example, reported that the flavour experts working on a descriptive panel at an international flavour house (who all had more than 3 years of experience flavour profiling food and drink products) exhibited just as much visual capture (or assimilation) of their orthonasal olfactory flavour judgments as did non-experts. Thus, based on the research that has been published to date, the most appropriate conclusion regarding flavour experts would appear to be that while some (specifically those with an expertise in wine) show an enhanced susceptibility to the crossmodal influence of colour on judgments within their area of expertise [142,145], this pattern of results does not necessarily extend to other groups of flavour experts [78].

\section{Genetic differences in the effect of colour}

Although surprisingly little studied to date, various genetic differences might also modulate the psychological effect of food colouring. Here, for example, one might think both of those individuals who are born colour blind (primarily males and constituting approximately $6 \%$ of the population; [146]). Presumably such differences in colour perception ought to have some impact of the psychological effect of food colour, though it is hard to find any published research on the topic (see http://www.colourblindawareness.org/colour-blindness/ living-with-colour-vision-deficiency/food/). Here, it is also worth noting that there are several discrete kinds of colour blindness, each likely affecting the perception of food and beverage colour in a slightly different way.

However, just as important as any deficits in colour perception, may be an individual's taster status. It turns out that genetic differences here may play an important role in determining just how much of a role colour plays in flavour perception. Some people have far more taste buds than others (the former are known as supertasters, the latter, non-tasters; with $25 \%$ of the population falling into each category). The remaining half of consumers fall into an intermediate group, known as medium tasters [147]. To give some idea of the differences in receptor density that might be involved here, it has been estimated that some individuals may have up to 14 times more taste buds than others [148]. Zampini et al. [68] have reported that supertasters are significantly less affected by the colour of a drink than medium tasters, who, in turn, are less affected than non-tasters (see Figure 5). It is somewhat surprising to find that this is the only study of the psychological impact of food colour to have assessed the taster status of their participants. ${ }^{j}$ One can, perhaps, frame this result in terms of the literature on sensory dominance. That is, those individuals with a greater number of taste buds presumably exhibit lower variance in terms of their unisensory gustatory judgments. According to the maximum likelihood account of multisensory integration [149], the perceptual estimate with the lower variance will likely be weighted more heavily when it comes to estimating a given stimulus attribute.

\section{Interim summary}

One cannot hope to attain a comprehensive understanding of the psychological impact of food colour without taking into account the individual differences. The relevant differences include genetic differences in terms of taster status and colour perception, as well as crosscultural and age-related differences. Although beyond the scope of this article, there may be racial differences in terms of colour preferences as well [150]. What is clear from the research that has been published to date is that these individual differences can influence both the meaning of colour and its influence on the consumer. Having established the importance of such individual differences (of both genetic and experiential origin), the question becomes one of how to assess the psychological impact of food colour experimentally. One solution here has been proposed in the work of Shankar and her colleagues [76-78].

According to Shankar et al. [77], assessing the 'degree of discrepancy' between the expected flavour set by colour and the flavour when eventually experienced by 


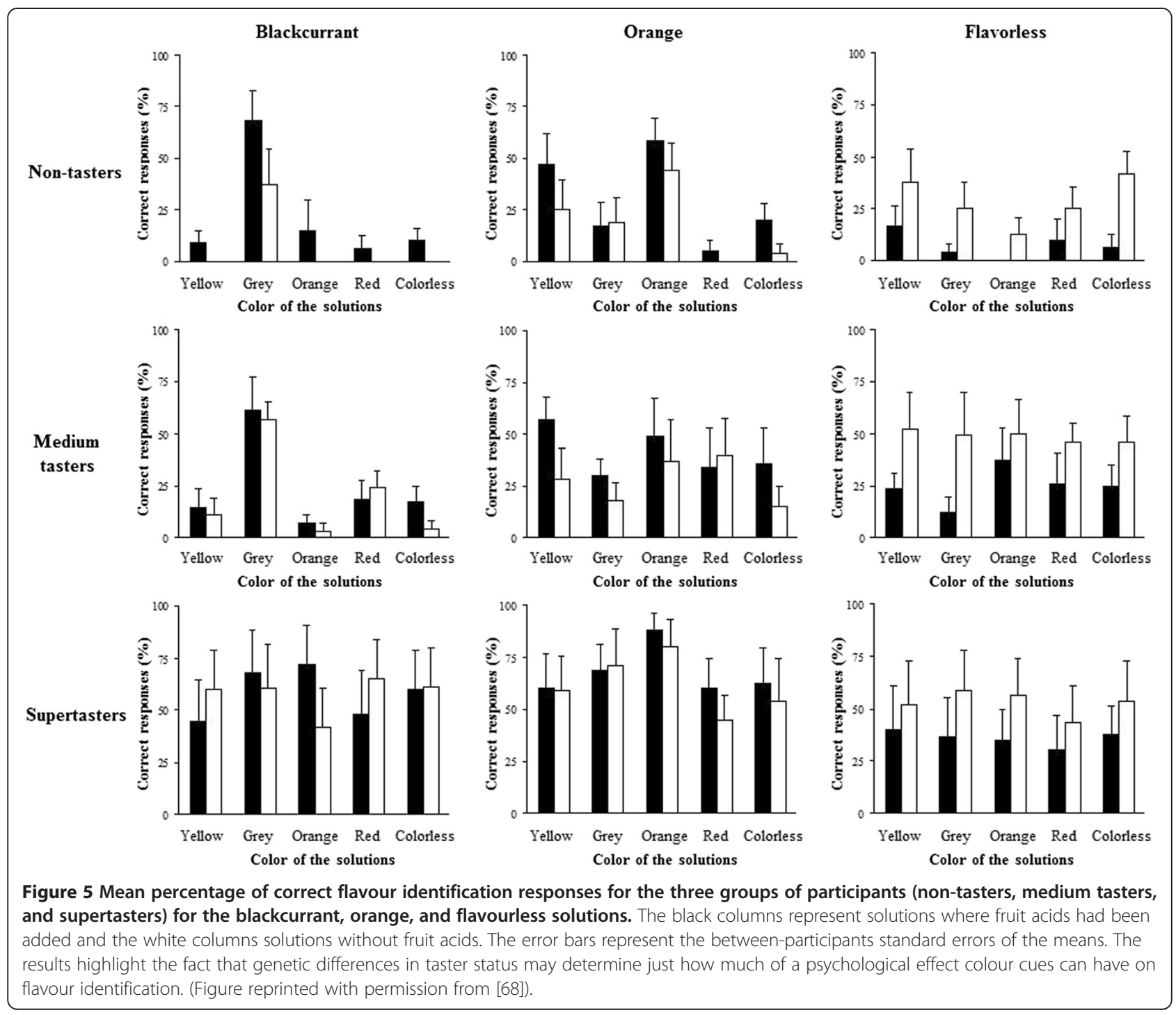

the participant (or consumer) is key to understanding when colour influences flavour perception. Shankar et al. argued that under conditions of low discrepancy, the perceived disparity between the expected and actual flavour of a drink (or food) is small. Low discrepancy colour-flavour combinations might, for example, consist of cranberry- or blueberry-flavoured drinks coloured purple (purple being associated with grape flavour), whereas high discrepancy combinations might include banana- or vanilla-flavoured drinks that have been coloured purple. Across several experiments, when a particular colour - identified by participants as one that generated a strong flavour expectation - was added to the drinks that the participants were given to sniff (as compared with when no such colour was added), a significantly greater proportion of their identification responses were consistent with this expectation. ${ }^{\mathrm{k}}$ By contrast, under conditions of high discrepancy, adding the same colours to the drinks no longer affected participants' identification responses in the same way (see Figure 6). That is, there was a significant difference in the proportion of responses that were consistent with participants' colourbased expectations in conditions of low as compared with high discrepancy. Shankar et al.'s results therefore demonstrate that the degree of discrepancy between an individual's expectation concerning the flavour (derived visually) and their actual experience on tasting the drink modulates the crossmodal influence of colour cues on judgments of flavour identity.

One thing to bear in mind about Shankar et al.'s [76-78] studies, though, is that the participants never got to taste the flavoured drinks that they were asked to judge. That is, all their judgments/ratings were made on the basis of nothing more that orthonasal olfactory cues. Of course, this should not matter all that much, given the extensive literature showing that colour cues can modulate 


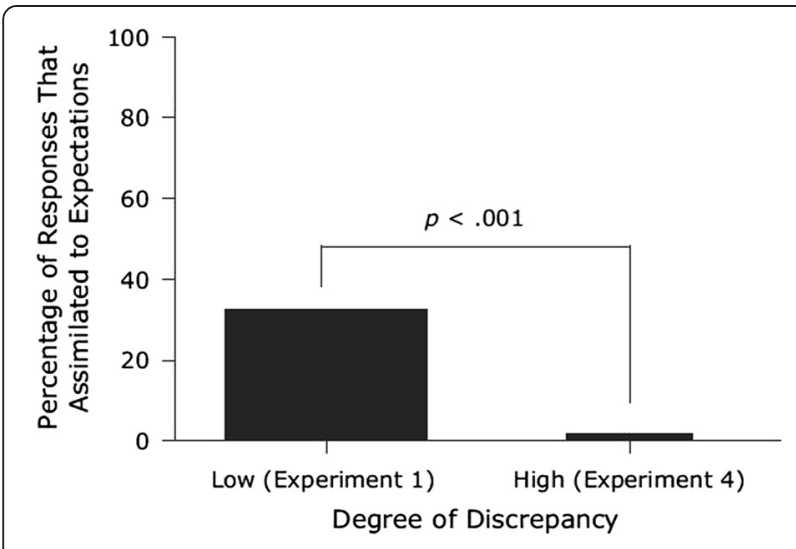

Figure 6 Summary results from two of the experiments (conducted with the same participants) reported by Shankar et al. [77] showing how the addition of food colouring to an otherwise colourless flavoured solution led to assimilation when the 'degree of discrepancy' between the flavour expected by the colour and the actual flavour of the drink when sniffed orthonasally was low, but not when the degree of discrepancy was high. (Figures reprinted with permission from [77]).

orthonasal olfactory discrimination/identification responses across a wide range of experimental conditions ([151-158]; see [159], for a review). ${ }^{1}$

\section{Bottom-up or top-down influences of colour}

Now, one further question that can, and probably should, be asked before closing concerns whether colour should be considered as exerting its psychological influence over flavour perception in more of a 'bottom-up' or more of a 'top-down' manner. On the one hand, it is clear that when people know that the colour they see is inappropriate (misleading) and so should be ignored, it nevertheless still influences their perception in a seemingly automatic manner $[47,68,145]$. Such results support a bottom-up account of at least part of colour's crossmodal influence over taste and flavour perception. Of course, the existence of such bottom-up effects should not be taken as evidence to deny the fact that top-down influences are also important.

Indeed, colour certainly also influence people's flavour perception in more of a top-down manner as well. Here, it is relevant to note that researchers have demonstrated that labelling, branding, and other descriptive information can all modify the meaning of a given food colour and by so doing influence the perceived taste of a food or beverage [1]. So, for instance, Shankar et al. [83] reported that, even when blindfolded, telling a participant that a sugar-coated chocolate candy has a particular colour (or that it is light or dark chocolate) influenced the pattern of responding that was observed. In a similar manner, a variety of nonsensory (labelling) cues have also been shown to bias the way in which a normally sighted observer interprets the meaning of a given colour (as in Yeomans et al.'s, [80], study). Taken together, then, there is good evidence that colour's psychological influence on taste and flavour perception occurs not only in a bottom-up but also in more of a top-down manner as well. Studying the interaction between these influences on flavour perception is an area of growing interest from both a theoretical and more marketing-inspired perspective [42,76,82]. A related challenge comes from trying to integrate the growing literature demonstrating the influence of everything from the colour of the product packaging [160] through to the colour of the lighting $[161,162]$ in which food and drink are consumed on the multisensory flavour experience [1].

\section{Conclusions}

Since the first reports that changing the colour of a food could change the taste/flavour were published [54,55], somewhere in the region of 150 papers have investigated the impact of food colouring on the perception and behaviour of participants/consumers. While the majority of those studies have tended to focus on colour's effect on taste/flavour identification (see [18], for a review), it is important to note that colour cues influence our food and drink-related behaviour in a number of different ways $[1,92,125,163]$. Food colouring undoubtedly plays an important role in driving liking and the consumer acceptability of a variety of food and beverage products. And while increasing colour variety in food can lead to enhanced consumption [92], what we see can also lead to a suppression of our appetitive behaviours when associated with off-colours (or coloration that is interpreted by the consumer as such).

Finally, given the practical difficulties associated with delivering flavours while a participant lies in the brain scanner [1], it is perhaps understandable that there has not been a great deal of neuroimaging research that has looked at the influence of colour on flavour perception as yet ([164]; see also [165]). Whether or not as the result of further neuroimaging, it is clear that additional research is most definitely needed in order to develop a better understanding of the psychological mechanisms underlying the various effects of colour on our perception of, and behaviours toward, food [166].

Certainly, the expectations, both sensory and hedonic, that are set by food colouring play an important role in determining the final flavour experience and how much it is liked. Furthermore, the degree of discrepancy between the sensory and hedonic expectations and the subsequent experience appears crucial to the question of whether assimilation or contrast will be observed. Here, recent research has increasingly demonstrated the differing meanings associated with food colour in different consumers. Identifying consistent colour-flavour mappings and training the consumer to internalize other new associations is one of the important challenges facing the food marketer interested 
in launching new products, or brand extensions, in a marketplace that is more colourful than ever.

\section{Endnotes}

'While the term 'product-intrinsic' is widely used in the literature when talking about the colour of a food or beverage, the appropriateness of this notion can be questioned from the perspective of (holistic) perception. Strictly speaking, colour is not a property of a (food) material but rather a percept in an observer that originates from an interaction with a material, under the influence of many other cues that are external to the coloured surface, but certainly internal to, the observer (for example, [167], p. 5).

${ }^{\mathrm{b}}$ Here, it is perhaps worth noting that intense food colouring, while seemingly attractive to children (see [138], for a review), may lead some consumers to consider a food or beverage product as being 'artificial' and hence less liked (for example, $[45,46]$ ).

${ }^{\mathrm{c}}$ Note that the participants in this study only ever had to report whether or not the solution had a taste. That is, they never had to identify the tastant. In fact, somewhat surprisingly, the question of whether colour influences the ability of people to identify/discriminate the basic tastes has not, as far as I am aware, been studied to date (see [18], for a review). This despite the fact that extensive evidence has been collected concerning the colours that people in different cultures associate with each of the basic tastes (see [40], for a review and crosscultural evidence).

${ }^{\mathrm{d}}$ Note that a lack of precise colour measurement has hampered comparison of the results of many of the studies that have been published to date (cf. $[4,168]$ ).

${ }^{\mathrm{e}} \mathrm{No}$ mention is made of whether ethical approval was obtained for this particular study!

${ }^{\mathrm{f}}$ Though note that olfactory cues are at least as important in people's judgment of whether a food has gone off ([169]; see also [170] on the consumer evaluation of the sensory properties of fish).

${ }^{g}$ Note that while under the majority of everyday conditions, people prefer foods and beverages that taste as they expect them to taste (that is, people do not like surprises, especially when it comes to the stimuli that enter the mouth, and hence have the potential to poison them), there are occasions, such as at the tables of the modernist restaurant where many diners seem to positively relish having their expectations played with $[1,125]$.

'These 'white strawberries' are the result of crossbreeding the South American strawberry Fragaria chiloensis, which grows wild in some parts of Chile, and the North American strawberry Fragaria virginiana.

${ }^{\mathrm{i}}$ Of course, here, it needs to be remembered that changing the colour of a drink can change its flavour perceptually. However, one has to imagine that any such crossmodal perceptual effects would have been picked up in consumer tests before the product was launched.

${ }^{j}$ Indeed, given the relatively small sample size and the post hoc nature of Zampini et al.'s [68] discovery, replication in a larger sample would undoubtedly be desirable to check on the generalizability of this potentially important result.

${ }^{\mathrm{k}}$ Here, it is worth pointing out that when flavour experts were tested, their results were similar to those of normal participants [78].

${ }^{1}$ That said, Koza et al.'s [56] results concerning the differing effect of colour on orthonasal and retronasal olfactory intensity judgments needs to be borne in mind here.

\section{Competing interests}

The author declares that he has no competing interests.

\section{Author's contributions}

CS wrote all parts of this review. The author read and approved the final manuscript.

\section{Acknowledgement}

CS would like to acknowledge the AHRC Rethinking the Senses grant (AH/L007053/1).

Received: 29 December 2014 Accepted: 6 March 2015

Published online: 22 April 2015

\section{References}

1. Spence C, Piqueras-Fiszman B. The perfect meal: the multisensory science of food and dining. Oxford: Wiley-Blackwell; 2014.

2. Cardello AV. The role of the human senses in food acceptance. In: Meiselman HL, MacFie HJH, editors. Food choice, acceptance and consumption. New York, NY: Blackie Academic and Professional; 1996. p. 1-82.

3. Clydesdale FM. The influence of colour on sensory perception and food choices. In: Walford J, editor. Developments in food colours-2. London, UK: Elsevier Applied Science; 1984. p. 75-112.

4. Clydesdale FM. Color perception and food quality. J Food Qual. 1991;14:61-74.

5. Clydesdale FM. Color as a factor in food choice. Crit Rev Food Sci Nutrit. 1993:33:83-101.

6. Delwiche JF. You eat with your eyes first. Physiol Behav. 2012;107:502-4

7. Hall RL. Flavor study approaches at McCormick and Company, Inc. In: In AD Little, Inc, editor. Flavor research and food acceptance: A survey of the scope of flavor and associated research, compiled from papers presented in a series of symposia given in 1956-1957. New York, NY: Reinhold; 1958. p. 224-240).

8. Kanig JL. Mental impact of colors in foods studied. Food Field Reporter. 1955;23:57.

9. Kostyla AS, Clydesdale FM. The psychophysical relationships between color and flavor. CRC Critic Rev Food Sci Nutrit. 1978;10:303-19.

10. Watson E: We eat with our eyes: flavor perception strongly influenced by food color, says DDW. Downloaded from http://www.foodnavigator-usa.com/ Science/We-eat-with-our-eyes-Flavor-perception-strongly-influenced-by-foodcolor-says-DDW on 19/12/2014.

11. Downham A, Collins P. Colouring our foods in the last and next millennium. Int J Food Sci Technol. 2000;35:5-22.

12. Tannahill R. Food in history. New York, NY: Stein and Day; 1973.

13. Walford J. Historical development of food coloration. In: Walford J, editor. Developments in food colours. London: Applied Science; 1980.

14. Crumpacker B. The sex life of food: when body and soul meet to eat. New York, NY: Thomas Dunne Books; 2006. 
15. Wheatley J: Putting colour into marketing. Marketing 1973, October:24-29, 67.

16. Rozin P. "Taste-smell confusions" and the duality of the olfactory sense. Percept Psychophys. 1982;31:397-401.

17. Spence C, Smith B, Auvray M. Confusing tastes and flavours. In: Stokes D, Matthen M, Biggs S, editors. Perception and its modalities. Oxford: Oxford University Press; 2015. p. 247-74.

18. Spence C, Levitan C, Shankar MU, Zampini M. Does food color influence taste and flavor perception in humans? Chemosens Percept. 2010;3:68-84

19. Deliza R, MacFie HJH. The generation of sensory expectation by external cues and its effect on sensory perception and hedonic ratings: a review. J Sens Stud. 1997;2:103-28.

20. Hutchings JB. Expectations and the food industry: the impact of color and appearance. New York, NY: Plenum Publishers; 2003.

21. Piqueras-Fizman B, Spence C. Sensory expectations based on product-extrinsic food cues: an interdisciplinary review of the empirical evidence and theoretical accounts. Food Qual Prefer. 2015;40:165-79.

22. Spence $C$. Eating with our ears: assessing the importance of the sounds of consumption to our perception and enjoyment of multisensory flavour experiences. Flavour. 2015:4:3

23. Cardello AV. Consumer expectations and their role in food acceptance. In: MacFie HJH, Thomson DMH, editors. Measurement of food preferences. London, UK: Blackie Academic \& Professional; 1994. p. 253-97.

24. Harris G: Colorless food? We blanch. The New York Times 2011, April 3:3. Downloaded from http://www.nytimes.com/2011/04/03/weekinreview/ 03harris.html?_r=0 on 21/12/2014

25. Murakoshi T, Masuda T, Utsumi K, Tsubota K, Wada Y. Glossiness and perishable food quality: visual freshness judgment of fish eyes based on luminance distribution. PLoS One. 2013;8(3):e58994.

26. Péneau S, Brockhoff PB, Escher F, Nuessli J. A comprehensive approach to evaluate the freshness of strawberries and carrots. Postharvest Biol Technol. 2007:45:20-9.

27. Prinz JF, \& de Wijk RA: Effects of flavor and visual texture on ingested volume. Poster presented at the 5th Meeting of the International Multisensory Research Forum. 2-5th June, Sitges, Spain; 2004.

28. Okajima K, \& Spence C: Effects of visual food texture on taste perception. i-Perception 2011, 2(8), http://i-perception.perceptionweb.com/journal/// article/ic966.

29. Lawless HT, Klein BP. Sensory science theory and applications in foods. New York, NY: Marcel Dekker; 1991.

30. Carlsmith JM, Aronson E. Some hedonic consequences of the confirmation and disconfirmation of expectancies. J Abnormal Social Psychol. 1963;66:151-6.

31. Schifferstein HNJ. Effects of product beliefs on product perception and liking. In: Frewer L, Risvik E, Schifferstein H, editors. Food, people and society: A European perspective of consumers' food choices. Berlin: Springer Verlag; 2001. p. 73

32. Zellner D, Strickhouser D, Tornow C. Disconfirmed hedonic expectations produce perceptual contrast, not assimilation. Am J Psychol. 2004;117:363-87

33. Spence C: Visual contributions to taste and flavour perception. In M. Scotter (Ed.), Colour additives for food and beverages. Cambridge, UK: Woodhead Publishing; in press.

34. Calvo C, Salvador A, Fiszman S. Influence of colour intensity on the perception of colour and sweetness in various fruit-flavoured yoghurts. European Food Res Technol. 2001;213:99-103.

35. Johnson J, Clydesdale FM. Perceived sweetness and redness in colored sucrose solutions. J Food Sci. 1982;47:747-52.

36. Johnson JL, Dzendolet E, Damon R, Sawyer M, Clydesdale FM. Psychophysical relationships between perceived sweetness and color in cherry-flavored beverages. J Food Protect. 1982;45:601-6.

37. Johnson JL, Dzendolet E, Clydesdale FM. Psychophysical relationships between perceived sweetness and redness in strawberry-flavored beverages. J Food Protect. 1983;46:21-5. 28.

38. Norton WE, Johnson FN. The influence of intensity of colour on perceived flavour characteristics. Medical Sci Res. 1987:15:329-30.

39. Maga JA. Influence of color on taste thresholds. Chem Senses Flavor. 1974:1:115-9.

40. Wan X, Woods AT, van den Bosch J, Mckenzie KJ, Velasco C, Spence C. Cross-cultural differences in crossmodal correspondences between tastes and visual features. Frontiers Psychol: Cognit. 2014;5:1365.
41. Clydesdale FM, Gover R, Philipsen DH, Fugardi C. The effect of color on thirst quenching, sweetness, acceptability and flavor intensity in fruit punch flavored beverages. J Food Qual. 1992;15:19-38.

42. Levitan C, Zampini M, Li R, Spence C. Assessing the role of color cues and people's beliefs about color-flavor associations on the discrimination of the flavor of sugar-coated chocolates. Chem Senses. 2008;33:415-23.

43. Lavin JG, Lawless HT. Effects of color and odor on judgments of sweetness among children and adults. Food Qual Prefer. 1998;9:283-9.

44. Alley RL, Alley TR. The influence of physical state and color on perceived sweetness. J Psychol. 1998;132:561-8.

45. Philipsen DH, Clydesdale FM, Griffin RW, Stern P. Consumer age affects response to sensory characteristics of a cherry flavored beverage. J Food Sci. 1995;60:364-8.

46. Chan MM, Kane-Martinelli C. The effect of color on perceived flavor intensity and acceptance of foods by young adults and elderly adults. J Am Dietetic Assoc. 1997;97:657-9.

47. Zampini M, Sanabria D, Phillips N, Spence C. The multisensory perception of flavor: assessing the influence of color cues on flavor discrimination responses. Food Qual Prefer. 2007;18:975-84.

48. Shermer DZ, Levitan CA. Red hot: the crossmodal effect of color intensity on piquancy. Multisensory Res. 2014;27:207-23.

49. Zhou X, Wan X, Mu B, Du D, \& Spence C: Examining colour-receptacleflavour interactions for Asian noodles. Food Qual Prefer in press.

50. Urbányi G. Investigation into the interaction of different properties in the course of sensory evaluation. I. The effect of colour upon the evaluation of taste in fruit and vegetable products. Acta Aliment. 1982;11:233-43.

51. Wadhwani R, McMahon DJ. Color of low-fat cheese influences flavor perception and consumer liking. J Dairy Science. 2012;95:2336-46.

52. Dolnick E: Fish or foul? The New York Times 2008, September 2, downloaded from http://www.nytimes.com/2008/09/02/opinion/02dolnick.html? _r=1\&scp=1\&sq=chocolate\%20strawberry\%20yogurt\&st=cse on 26/12/14.

53. DuBose CN, Cardello AV, Maller O. Effects of colorants and flavorants on identification, perceived flavor intensity, and hedonic quality of fruit-flavored beverages and cake. J Food Sci. 1980;45:1393-9. 1415.

54. Moir HC. Some observations on the appreciation of flavour in foodstuffs J Soc Chemical Ind: Chem Ind Rev. 1936;14:145-8.

55. Duncker $\mathrm{K}$. The influence of past experience upon perceptual properties. Am J Psychol. 1939:52:255-65.

56. Koza BJ, Cilmi A, Dolese M, Zellner DA. Color enhances orthonasal olfactory intensity and reduces retronasal olfactory intensity. Chem Senses. 2005;30:643-9.

57. Frank RA, Ducheny K, Mize SJS. Strawberry odor, but not red color, enhances the sweetness of sucrose solutions. Chem Senses. 1989;14:371-7.

58. Bayarri S, Calvo C, Costell E, Duran L. Influence of color on perception of sweetness and fruit flavor of fruit drinks. Food Sci Technol Int. 2001;7:399-404.

59. Fernández-Vázquez R, Hewson L, Fisk I, Vila D, Mira F, Vicario IM, et al. Colour influences sensory perception and liking of orange juice. Flavour. 2014;3:1.

60. Gifford SR, Clydesdale FM. The psychophysical relationship between color and sodium chloride concentrations in model systems. J Food Protect. 1986;49:977-82.

61. Gifford SR, Clydesdale FM, Damon Jr RA. The psychophysical relationship between color and salt concentrations in chicken flavored broths. J Sensory Stud. 1987:2:137-47.

62. McCullough JM, Martinsen CS, Moinpour R. Application of multidimensional scaling to the analysis of sensory evaluations of stimuli with known attribute structures. J Applied Psychol. 1978;65:103-9.

63. Pangborn RM. Influence of color on the discrimination of sweetness. Am J Psychol. 1960;73:229-38.

64. Pangborn RM, Hansen B. The influence of color on discrimination of sweetness and sourness in pear-nectar. Am J Psychol. 1963;76:315-7.

65. Roth HA, Radle LJ, Gifford SR, Clydesdale FM. Psychophysical relationships between perceived sweetness and color in lemon- and lime-flavored drinks. J Food Sci. 1988:53:1116-9. 1162.

66. Strugnell C. Colour and its role in sweetness perception. Appetite. 1997;28:85.

67. Oram N, Laing DG, Hutchinson I, Owen J, Rose G, Freeman M, et al. The influence of flavor and color on drink identification by children and adults. Develop Psychobiol. 1995;28:239-46.

68. Zampini M, Wantling E, Phillips N, Spence C. Multisensory flavor perception: assessing the influence of fruit acids and color cues on the perception of fruit-flavored beverages. Food Qual Prefer. 2008;19:335-43. 
69. Garber Jr LL, Hyatt EM, Starr Jr RG. The effects of food color on perceived flavor. J Market Theory Practice. 2000;8(4):59-72.

70. Hyman A. The influence of color on the taste perception of carbonated water preparations. Bull Psychon Soc. 1983:21:145-8.

71. Stillman J. Color influences flavor identification in fruit-flavored beverages. J Food Sci. 1993;58:810-2.

72. Guinard JX, Souchard A, Picot M, Rogeaux M, Siefferman JM. Sensory determinants of the thirst-quenching character of beer. Appetite. 1998:31:101-15.

73. Zellner DA, Durlach P. What is refreshing? An investigation of the color and other sensory attributes of refreshing foods and beverages. Appetite. 2002;39:185-6.

74. Zellner DA, Durlach P. Effect of color on expected and experienced refreshment, intensity, and liking of beverages. Am J Psychol. 2003;116:633-47.

75. Shankar MU, Levitan C, Spence C. Grape expectations: the role of cognitive influences in color-flavor interactions. Conscious Cognit. 2010;19:380-90,

76. Shankar M, Simons C, Levitan C, Shiv B, McClure S, Spence C. An expectations-based approach to explaining the crossmodal influence of color on odor identification: the influence of temporal and spatial factors. J Sensory Stud. 2010;25:791-803.

77. Shankar M, Simons C, Shiv B, Levitan C, McClure S, Spence C. An expectations-based approach to explaining the influence of color on odor identification: the influence of degree of discrepancy. Attent Percept Psychophys. 2010;72:1981-93.

78. Shankar M, Simons C, Shiv B, McClure S, Spence C. An expectation-based approach to explaining the crossmodal influence of color on odor identification: the influence of expertise. Chemosens Percept. 2010;3:167-73.

79. Piqueras-Fiszman B, Spence C. Crossmodal correspondences in product packaging: assessing color-flavor correspondences for potato chips (crisps). Appetite. 2011;57:753-7.

80. Yeomans $\mathrm{M}$, Chambers $\mathrm{L}, \mathrm{Blumenthal} \mathrm{H}$, Blake $\mathrm{A}$. The role of expectancy in sensory and hedonic evaluation: the case of smoked salmon ice-cream. Food Qual Prefer. 2008;19:565-73.

81. Hoegg J, Alba JW. Taste perception: more than meets the tongue. J Consumer Res. 2007:33:490-8.

82. Miller EG, Kahn BE. Shades of meaning: the effect of color and flavor names on consumer choice. J Consumer Res. 2005:32:86-92.

83. Shankar MU, Levitan CA, Prescott J, Spence C. The influence of color and label information on flavor perception. Chemosens Percept. 2009:2:53-8.

84. Lelièvre M, Chollet $\mathrm{S}$, Abdi H, Valentin D. Beer-trained and untrained assessors rely more on vision than on taste when they categorize beers. Chemosens Percept. 2009:2:143-53.

85. Garber Jr LL, Hyatt EM, Starr Jr RG. Placing food color experimentation into a valid consumer context. J Food Products Market. 2001:7(3):3-24

86. Garber Jr LL, Hyatt EM, Starr Jr RG. Measuring consumer response to food products. Food Qual Prefer. 2003:14:3-15.

87. Garber Jr LL, Hyatt EM, Starr Jr RG. Reply to commentaries on: "Placing food color experimentation into a valid consumer context". Food Qual Prefer. 2003;14:41-3.

88. Wan X, Velasco C, Michel C, Mu B, Woods AT, Spence C. Does the shape of the glass influence the crossmodal association between colour and flavour? A cross-cultural comparison. Flavour. 2014;3:3.

89. Wan X, Woods AT, Seoul KH, Butcher N, Spence C. When the shape of the glass influences the flavour associated with a coloured beverage: evidence from consumers in three countries. Food Qual Prefer. 2015;39:109-16.

90. Spence C. Drinking in colour. Cocktail Lovers. 2014;13:28-9.

91. Birren F. Color and human appetite. Food Technol. 1963;17(May):45-7.

92. Piqueras-Fiszman B, Spence C. Colour, pleasantness, and consumption behaviour within a meal. Appetite. 2014;75:165-72

93. de Wijk RA, Polet IA, Engelen L, van Doorn RM, Prinz JF. Amount of ingested custard dessert as affected by its color, odor, and texture. Physiol Behav. 2004;82:397-403.

94. Gossinger M, Mayer F, Radochan N, Höfler M, Boner A, Grolle E, et al. Consumer's color acceptance of strawberry nectars from puree. J Sensory Stud. 2009;24:78-92.

95. Imram $\mathrm{N}$. The role of visual cues in consumer perception and acceptance of a food product. Nutrit Food Sci. 1999:99:224-30.

96. Schutz HG. Color in relation to food preference. In: Farrell KT, Wagner JR, Peterson MS, MacKinney G, editors. Color in foods: A symposium sponsored by the Quartermaster Food and Container Institute for the Armed Forces
Quartermaster Research and Development Command U. S. Army Quartermaster Corps. Washington: National Academy of Sciences - National Research Council; 1954. p. 16-23.

97. Wei ST, Ou LC, Luo MR, Hutchings JB. Optimization of food expectations using product colour and appearance. Food Qual Prefer. 2012;23:49-62.

98. Wilson T, Klaaren K. Expectation whirls me round: the role of affective expectations on affective experiences. In: Clear MS, editor. Review of personality and social psychology: Emotion and social behavior. Newbury Park: Sage; 1992. p. 1-31.

99. Rolls BJ, Rowe EA, Rolls ET. How sensory properties of foods affect human feeding behaviour. Physiol Behav. 1982;29:409-17.

100. Geier A, Wansink B, Rozin P. Red potato chips: segmentation cues can substantially decrease food intake. Health Psychol. 2012;31:398-401.

101. Kahn BE, Wansink B. The influence of assortment structure on perceived variety and consumption quantities. J Consumer Res. 2004;30:519-33.

102. Redden JP, Hoch SJ. The presence of variety reduces perceived quantity. J Consumer Res. 2009:36:406-17.

103. Tepper BJ. Effects of a slight color variation on consumer acceptance of orange juice. J Sens Stud. 1993:8:145-54.

104. Accum F: A treatise on adulteration of food and culinary poisons. Cited in Anon. (1980): 1820

105. Anon. Colourings - an interim review. Int Flavours Food Additives. 1979;10(3):96-7.

106. Anon. Additive use triggers consumer food concerns. Food Product Develop. 1979;13(8):8.

107. Anon. Food colors. A scientific status summary by the Institute of Food Technologists' Expert Panel on Food Safety \& Nutrition and the Committee on Public Information. Food Technol. 1980;34(7):77-84.

108. Goldenberg N. Colours - do we need them? In British Nutrition Foundation (Ed.), Why food additives? The safety of foods (pp. 22-24). London, UK: Forbes Publications; 1977.

109. Kramer A. Benefits and risks of color additives. Food Technol. 1978;32(8):65-7.

110. Lucas CD, Hallagan JB, Taylor SL. The role of natural color additives in food allergy. Advances Food Nutrit Res. 2001;43:195-216.

111. Meggos H. Food colours: an international perspective. Manufacturing Confectioner. 1995;75:59-65.

112. Stevens LJ, Kuczek T, Burgess JR, Stochelski MA, Eugene Arnold L, Galland L. Mechanisms of behavioral, atopic, and other reactions to artificial food colors in children. Nutrit Rev. 2013:71:268-81.

113. Tuorila-Ollikainen $\mathrm{H}$. Pleasantness of colourless and coloured soft drinks and consumer attitudes to artificial food colours. Appetite. 1982;3:369-76.

114. Weiss B, Williams JH, Margen S, Abrams B, Caan B, Citron LJ, et al. Behavioral responses to artificial food colors. Science. 1980;207:1487-9.

115. Whitehill I. Human idiosyncratic responses to food colours. Food Flavour Ingred Packag Process. 1980;1(7):23-7. 37.

116. Wilson B. Swindled: from poison sweets to counterfeit coffee - the dark history of the food cheats. London: John Murray; 2009.

117. Patel A. Going green: tuneable colloidal colour blends from natural colourants. New Food Magazine. 2014;17(2):7-9.

118. Bridle P, Timberlake CF. Anthocyanins as natural food colours-selected aspects. Food Chem. 1997;58:103-9.

119. Tolliday S. Nestlé confectionary: journey with colours. New Food Magazine. 2012;13(6):27-31

120. Wissgott U, Bortlik K. Prospects for new natural food colorants. Trends Food Sci Technol. 1996;7:298-302.

121. Dalby A. Food in the Ancient World from A to Z. London, UK: Routledge; 2003.

122. Greene W. Vegetable gardening the Colonial Williamsburg Way: 18th century methods for today's organic gardeners. Rodale: New York, NY; 2012.

123. Macrae F: What's for dinner? Rainbow coloured carrots and super broccoli that's healthier and sweeter. DailyMail Online 2011, 15 October. Available at http://www.dailymail.co.uk/health/article-2044695/Purple-carrots-saleTescosupermarket-Orange-year.html (accessed January 2014).

124. Cook W: Would you eat a 'gourmet' burger made with charred bamboo and squid ink? Daily Mail Online 2012, 25th September. Downloaded from: http://www.dailymail.co.uk/news/article-2208321/Burger-King-black-burgerJapan-bamboo-charcoal-squid-ink.html.

125. Anon: 'Anything' and 'Whatever' beverages promise a surprise, every time. Press release, 17th May; 2007.

126. Garber Jr LL, Hyatt EM, Boya UO. The mediating effects of the appearance of nondurable consumer goods and their packaging on consumer behavior. In: Schifferstein HNJ, Hekkert P, editors. Product experience. London, UK: Elsevier; 2008. p. 581-602. 
127. Walsh LM, Toma RB, Tuveson RV, Sondhi L. Color preference and food choice among children. J Psychol. 1990;124:645-53.

128. Piqueras-Fiszman B, Spence C. Sensory incongruity in the food and beverage sector: art, science, and commercialization. Petits Propos Culinaires. 2012;95:74-118.

129. Favre JP, November A. Colour and communication. Zurich: ABC-Verlag; 1979.

130. Gimba JG. Color in marketing: shades of meaning. Marketing News. 1998:32(6):16.

131. Hicks D. Benefits of added colourings in food and drinks. Int Flavours Food Additives. 1979;10(1):31-2.

132. Singh S. Impact of color on marketing. Manag Decis. 2006:44:783-9.

133. Garber LL, Hyatt EM, \& Nafees L: The effects of food color on perceived flavor: a factorial investigation in India. J Food Products Market 2015 (in press).

134. Masurovsky BI. How to obtain the right food color. Food Industries. 1939;11 (13):55-6.

135. Farrell G: What's green. Easy to squirt? Ketchup! USA Today 2000, Monday July 10:2b.

136. Triplett T. Consumers show little taste for clear beverages. Market News. 1994;28(11):2. 11

137. Christensen C. Effect of color on judgments of food aroma and food intensity in young and elderly adults. Percept. 1985;14:755-62.

138. Spence $C$. The development and decline of multisensory flavour perception. In: Bremner AJ, Lewkowicz D, Spence C, editors. Multisensory development. Oxford, UK: Oxford University Press; 2012. p. 63-87.

139. Gori M, Del Viva M, Sandini G, Burr DC. Young children do not integrate visual and haptic information. Curr Biol. 2008;18:694-8.

140. Cheskin L. How to predict what people will buy. New York, NY: Liveright; 1957.

141. Hine T. The total package: the secret history and hidden meanings of boxes, bottles, cans, and other persuasive containers. New York, NY: Little Brown; 1995.

142. Pangborn RM, Berg HW, Hansen B. The influence of color on discrimination of sweetness in dry table-wine. Am J Psychol. 1963;76:492-5.

143. Spence C. The color of wine - part 1. The World of Fine Wine. 2010:28:122-9.

144. Morrot G, Brochet F, Dubourdieu D. The color of odors. Brain Lang. 2001;79:309-20.

145. Parr W, White KG, Heatherbell D. The nose knows: influence of colour on perception of wine aroma. J Wine Res. 2003;14:79-101.

146. Broackes J. What do the color-blind see? In: Cohen J, Matthen M, editors. Color ontology and color science. Cambridge, MA: MIT Press; 2010. p. 291-389.

147. Bartoshuk LM. Comparing sensory experiences across individuals: recent psychophysical advances illuminate genetic variation in taste perception Chem Senses. 2000;25:447-60.

148. Miller IJ, Reedy DP. Variations in human taste bud density and taste intensity perception. Physiol Behav. 1990:47:1213-9.

149. Ernst MO, Banks MS. Humans integrate visual and haptic information in a statistically optimal fashion. Nature. 2002;415:429-33.

150. Scanlon BA. Race differences in selection of cheese color. Percept Motor Skills. 1985;61:314.

151. Blackwell L. Visual clues and their effects on odour assessment. Nutrit Food Sci. 1995;5:24-8.

152. Davis RG. The role of nonolfactory context cues in odor identification. Percept Psychophys. 1981;30:83-9.

153. Michael GA, Galich H, Relland S, Prud'hon S. Hot colors: the nature and specificity of color-induced nasal thermal sensations. Behaviour Brain Res. 2010;207:418-28.

154. Petit CEF, Hollowood TA, Wulfert F, Hort J. Colour-coolant-aroma interactions and the impact of congruency and exposure on flavour perception. Food Qual Prefer. 2007;18:880-9.

155. Stevenson RJ, Oaten M. The effect of appropriate and inappropriate stimulus color on odor discrimination. Percept Psychophys. 2008;70:640-6.

156. Zellner DA, Bartoli AM, Eckard R. Influence of color on odor identification and liking ratings. Am J Psychol. 1991;104:547-61.

157. Zellner DA, Kautz MA. Color affects perceived odor intensity. J Exp Psychol: Hum Percept Perf. 1990;16:391-7.

158. Zellner DA, Whitten LA. The effect of color intensity and appropriateness on color-induced odor enhancement. Am J Psychol. 1999:112:585-604.

159. Zellner DA. Color-odor interactions: a review and model. Chemosens Percept. 2013:6:155-69.
160. Spence C, Piqueras-Fiszman B. The multisensory packaging of beverages. In: Kontominas MG, editor. Food packaging: Procedures, management and trends. Hauppauge NY: Nova Publishers; 2012. p. 187-233.

161. Oberfeld D, Hecht $H$, Allendorf U, Wickelmaier F. Ambient lighting modifies the flavor of wine. J Sens Stud. 2009;24:797-832.

162. Spence C, Velasco C, Knoeferle K. A large sample study on the influence of the multisensory environment on the wine drinking experience. Flavour. 2014;3:8.

163. Maga JA. Influence of freshness and color on potato chip sensory preferences. J Food Sci. 1973;38:1251-2.

164. Skrandies W, Reuther N. Match and mismatch of taste, odor, and color is reflected by electrical activity in the human brain. J Psychophysiol. 2008:22:175-84.

165. Österbauer RA, Matthews PM, Jenkinson M, Beckmann CF, Hansen PC, Calvert GA. Color of scents: chromatic stimuli modulate odor responses in the human brain. J Neurophysiol. 2005;93:3434-41.

166. Kappes SM, Schmidt SJ, Lee SY. Color halo/horns and halo-attribute dumping effects within descriptive analysis of carbonated beverages. J Food Sci. 2006:71:S590-5.

167. Shepherd GM. Neurogastronomy: how the brain creates flavor and why it matters. New York: Columbia University Press; 2012

168. Francis FJ, Clydesdale FM. Food colorimetry: theory and applications. New York, NY: Van Nostrand Reinhold/AVl; 1975

169. Boesveldt S, Frasnelli J, Gordon AR, Lündstrom JN. The fish is bad: negative food odors elicit faster and more accurate reactions than other odors. Biol Psychol. 2010;84:313-7.

170. Sawyer FM, Cardello AV, Prell PA. Consumer evaluation of the sensory properties of fish. J Food Sci. 1988:53:12-8. 24

\section{Submit your next manuscript to BioMed Central and take full advantage of:}

- Convenient online submission

- Thorough peer review

- No space constraints or color figure charges

- Immediate publication on acceptance

- Inclusion in PubMed, CAS, Scopus and Google Scholar

- Research which is freely available for redistribution 